\title{
ÉTICA E GLOBALIZAÇÃO
}

Xavier Pintado*

\section{INTRODUÇÃO}

O mundo mudou. E mudou profundamente nos últimos tempos, nomeadamente nas duas últimas décadas. Ao iniciar um debate sobre a humanização da economia, interrogando-se sobre "A Economia, que futuro?", no Centre Catholique International, em Genebra, na transição de Século e de Milénio, o Presidente começou com a afirmação de que "O mundo que temos debaixo dos pés não é já o mundo que temos nas nossas cabeças". Isto, não apenas para aqueles que nasceram na primeira metade do séc. XX, mas mesmo para as novas gerações que encontram igualmente dificuldade em situar-se neste mundo em rápida mudança. Numa tentativa de caracterização do século XX, do século que se encerrava, com os horrores do Goulag e do Holocausto, as catástrofes das duas guerras mundiais e os conflitos étnicos que, no conjunto, dizimaram mais vidas do que todas as guerras que as precederam; e, ao mesmo tempo, com o impressionante avanço da ciência e das tecnologias, o autor concluía que se tivesse de caracterizar esse século por uma única palavra, essa palavra seria:

\footnotetext{
* Professor da Universidade Católica Portuguesa.
} 
mudança. E a mudança, ao confrontar-nos com as novas realidades e problemas, a um ritmo a que temos dificuldade de acomodar-nos, põenos numerosas interrogações e dilemas éticos. Com opções comportamentais fundamentais para o homem e para os povos e o seu destino. "The GWorld", ou Globalização - palavra ou realidade, também ela de mudança - tem dominado as atenções ou preocupações da transição do Século, confronta-nos com novos desafios e problemas de carácter ético. Donde a importância do tema que nos é proposto. Trata-se de uma tema vasto e complexo, com várias dimensões, que vamos procurar tratar fundamentalmente numa das suas vertentes - a económica - sem, todavia, deixar de referir outras, também importantes do ponto de vista ético e de acentuar o facto de que reduzir os problemas da globalização aos seus aspectos económicos é empobrecê-lo.

\section{O CONCEITO DE GLOBALIZAÇÃO}

O que é, afinal, esse tão falado fenómeno da globalização? Procurando encará-lo numa perspectiva ampla, que transcende o aspecto puramente económico, Anthony Giddens nota que a globalização envolve uma transição da forma espacial de organização da actividade humana para um padrão transcontinental ou interregional e uma interacção crescente no exercício do poder. O que implica uma extensão e um aprofundamento das relações sociais e institucionais no espaço e no tempo, de modo tal que as actividades correntes, ou de cada dia, são cada vez mais influenciadas por acontecimentos que ocorrem do outro lado do planeta e dão às práticas e decisões de grupos ou comunidades locais um impacto ou reverberação que pode ter expressão ou significado global.

A definição é complicada e de difícil retenção, mas põe em evidência dois aspectos fundamentais da globalização: a lateração da dimensão espacial dos actos dos homens e grupos humanos e a interdependência crescente desses actos e comunidades humanas. 
Um outro autor, Goldblatt, põe igualmente o acento nestes dois aspectos ou características da globalização: no facto de várias categorias da actividade humana - a política, a económica e a social assumirem um âmbito universal e a intensificação dos níveis de interacção ou interdependência dos Estados e grupos sociais.

Numa perspectiva mais restrita - essencialmente económica - o World Economic Outlook do Fundo Monetário Internacional de 1997 descreve o fenómeno da globalização como "a crescente interdependência económica dos países no âmbito mundial, mediante um volume crescente e uma variedade de transacções de bens, serviços e fluxos de capitais através das fronteiras e a mais rápida e ampla difusão de tecnologias.

Esse movimento de globalização ou mundialização da economia envolve, segundo a OCDE, três aspectos ou linhas distintas:

a) A internacionalização ou desenvolvimento dos fluxos de trocas entre países (em vez de dentro de um mesmo país) - como no caso das uvas e pêssegos espanhóis, com odor mas sem sabor, em substituição da tradicional e saborosa fruta portuguesa.

b) A transnacionalidade - na localização ou implantação de empresas e fluxos de investimento (deslocalização), dependente da liberdade de estabelecimento, e a procura de dimensão à escala mundial, dando lugar a um número e volume de fusões e aquisições sem precedente.

c) E a globalização propriamente dita que corresponde à criação ou desenvolvimento de redes mundiais de produção, distribuição e informação.

\section{MANIFESTAÇÕES OU ANTECEDENTES HISTÓRICOS DA GLO-BALIZAÇÃO}

Embora tido como um fenómeno do nosso tempo, e sobretudo de fim de século, associado em boa medida à revolução nas tecnologias 
da informação, a globalização, como a moeda única e outras formas de unificação de mercados, teve os seus antecedentes históricos.

Enquanto o termo apareceu no uso corrente, nos anos 80 nos EUA, para designar o reforço das interdependências de economias e a multiplicação das redes mundiais, quer de informação, quer de distribuição e colaboração entre instituições a nível transnacional, o fenómeno teve precedentes históricos importantes, alguns longínquos mas com características diferentes do presente como o encontro de povos e culturas e o confronto cultural e de troca de bens. E os portugueses foram, em certo sentido, os pioneiros da globalização, tendo os desenvolvimentos no séc. XVI constituído aquilo a que alguém chamou o primeiro encontro do Mundo - na sua diversidade - consigo próprio.

Nesse momento rasgou-se à humanidade uma vastidão e confronto de realidades que ela não podia sequer imaginar, na simplicidade da vivência da sociedade das eras precedentes e mesmo no quadro renascentista da época.

As caravelas lusitanas constituíram, assim, o primeiro veículo da globalização e do diálogo de culturas e civilizações.

Depois, portugueses, espanhóis, holandeses, franceses e ingleses prosseguiram, na rota das caravelas, a explorações e troca de riquezas.

Um amplo grau de liberalização das trocas e dos movimentos de capitais também não é exclusivo dos nossos dias. A liberdade de circulação de bens, pessoas e capitais foi mesmo maior que a de hoje, na $2^{\mathrm{a}}$ metade do séc. XIX e início do séc. XX, até à $1^{\mathrm{a}}$ Guerra Mundial.

Nesse período, a globalização foi desencadeada ou propiciada pela redução e eliminação das barreiras às trocas entre países sob o regime liberal e a hegemonia britânica conhecidos por "Pax Britanica". E essas mesmas trocas foram, em larguíssima medida, facilitadas pela redução acentuada dos custos de transporte graças a uma revolução tecnológica traduzida no desenvolvimento dos caminhos-de-ferro e da navegação que estiveram na base da $1^{\mathrm{a}}$ Revolução Industrial. 
O que é novo ou característico dos nossos dias é a dimensão ou volume atingido pelas trocas de bens e serviços a nível mundial e a instantaneidade das operações, especialmente de capitais, permitida pela revolução da informação, e que deu origem ao chamado fenómeno da "financiarização", ou crescimento muito mais rápido e acentuado do volume de operações financeiras que o crescimento do produto.

O actual processo de globalização diferencia-se dos anteriores no seu âmbito, profundidade e características ou base institucional. É verdadeiramente global ou universal, multidimensional e propulsionado por poderosas forças económicas operando num sistema único de relações: o de mercado.

De resto, em certos aspectos ou vertentes, a economia mundial da $2^{\mathrm{a}}$ metade do séc. XIX e do período que antecedeu a $1^{\mathrm{a}}$ Guerra Mundial atingiu mesmo um maior grau de integração que nos nossos dias, tendo o volume relativo de fundos que deixaram a Europa com destino aos Estados Unidos e aos países ditos de "recent settlement" (Argentina, Austrália e Nova Zelândia, especialmente) excedido largamente os actuais investimentos no exterior.

Esta ampla liberdade de movimentos, de fluxos de bens e de capitais, e sobretudo de pessoas, tão bem epitomizada num texto magnífico de Keynes, e que na altura se considerava parte de uma ordem natural e permanente, foi subitamente sustada pela $1^{\text {a }}$ Guerra Mundial e pelas restrições aos movimentos de capitais impostos pelas necessidades de financiamento da guerra.

E essa suspensão inesperada e abruta põe hoje também o problema de saber se essa "terrível" - na opinião de alguns - globalização, com todo o cortejo de males e injustiças que lhe atribuem, está destinada a perdurar ou constitui simplesmente um fenómeno transitório, espécie de doença do tempo, que há que atacar e curar, como muitos pretendem.

Ou, como o semanário britânico The Economist põe o problema num dos seus School Briefs (18/10/97), saber se o movimento de globalização poderá ser sustado ou invertido outra vez. 
A resposta é a de que será agora bastante mais difícil fazê-lo do que então. E isto pelas razões seguintes:

$1^{\text {a }}$ As novas tecnologias e os novos tipos de instrumentos financeiros tornam bastante mais difícil a imposição de controlos efectivos dos movimentos de capitais e os países que o tentarem sofrerão seriamente com isso.

$2^{\mathrm{a}}$ A importância e características das empresas multinacionais, com a possibilidade que hoje têm de transferir produções de um país ou região para outra, tornam custosa a introdução de barreiras ao comércio de bens e serviços. Além disso as novas tecnologias têm permitido desenvolver canais de distribuição que uma política proteccionista teria dificuldade em bloquear, nomeadamente no que toca à distribuição de filmes e informação.

$3^{\mathrm{a}} \mathrm{A}$ liberdade de comércio possui hoje bases ou fundamentos institucionais (Organização Mundial do Comércio e Acordos Preferenciais Regionais), dos quais é difícil sair sem incorrer em custos elevados, sobretudo em face da experiência manifesta de que a abertura ao exterior promove ou contribui para o desenvolvimento e a prosperidade das nações, enquanto o isolacionismo e a protecção levam ao seu empobrecimento.

\section{3. ÉTICA E GLOBALIZAÇÃO}

Qual é, então, a relação entre a globalização e ética, ou, quais são os problemas éticos postos pela globalização?

Não são poucos e, todavia, seríamos tentados a dizer, com Václav Havel, perante a fúria dos protestos de Praga contra essas duas faces ou expressões da globalização que são o Fundo Monetário Internacional e o Banco Mundial, que a globalização é ética ou moralmente neutra, e que "os mesmos movimentos tanto podem conduzir a humanidade a horrores como a um futuro melhor". Por outras palavras, que a globalização se apresenta como um fenómeno 
ambivalente, com aspectos ou consequências muito positivas mas, ao mesmo tempo, também com incidências negativas.

É, de resto, aquilo que afirma o Papa Paulo VI n Populorum Progressio ao referir que "Qualquer crescimento é ambivalente. Embora necessário para permitir ao homem ser mais homem, torna-o, contudo, prisioneiro no momento em que se transforma no bem supremo que impede de ver mais além".

A globalização é um processo de abertura de mercados e de esbater de fronteiras, combinado com uma revolução de tecnologias. Um movimento que abre amplas perspectivas e potencialidades aos povos, mas que tem também custos e efeitos desfavoráveis para alguns, que é preciso enfrentar ou compensar e corrigir mediante políticas adequadas a nível nacional e mundial mediante acções de cooperação internacional e uma oferta mais ampla e adequada de bens públicos globais.

Em termos gerais pode afirmar-se, com base numa evidência factual indesmentível, que a globalização promove a eficiência e a inovação, cria riqueza ou prosperidade, conduzindo mesmo a uma maior igualdade em algumas sociedades e regiões do mundo.

Mas os ajustamentos que envolve nos padrões de produção, comércio e investimento, têm um custo e não são facilmente introduzidos por todos os povos ou sociedades. Donde a preocupação de que alguns grupos sociais, regiões ou países que não consigam acompanhar o processo e sejam deixados para trás ou marginalizados.

A evidência disponível mostra que nos países desenvolvidos o rendimento per capita triplicou no último meio século, o qual conheceu um período de liberalização de mercados e de movimentos de capitais e, ao mesmo tempo, de crescimento sem precedentes e que esse factor multiplicativo se aplica, com ligeira diferença, igualmente aos países em vias de desenvolvimento no seu conjunto. $\mathrm{O}$ que corresponde a dizer, a 4/5 da humanidade. Mas países houve também, nomeadamente na África ao Sul do Sahará - com ligeiramente mais $1 / 10$ da população mundial - que praticamente não participaram nessa melhoria. Assim, a disparidade de rendimentos per capita entre a $5^{\text {a }}$ 
parte mais rica da população mundial e a $5^{\mathrm{a}}$ mais pobre, passou de 30 para 1 em 1960, para 74 para 1 em 1997, cavando-se fossos profundos de desigualdades entre países e regiões do globo. Tal parece ter sido devido a problemas culturais, a um meio natural desfavorável e sobretudo às suas instituições, nomeadamente, às guerras e conflitos étnicos e à forma como são governados esses povos.

O mesmo sucedeu entre regiões no seio de alguns países como a União Indiana e a China onde, não obstante as melhorias substanciais conseguidas para amplas massas das suas populações, se cavaram igualmente fossos profundos entre zonas ou regiões.

Parte destas diferenças entre países é devida às suas instituições e às políticas por eles prosseguidas.

Com efeito, não se vê como se pode assegurar o progresso económico (e não só) em países com governos incompetentes e corruptos, assolados pela guerra, onde o direito de propriedade não é respeitado nem a lei é observada.

Assim, estima-se que cerca de $40 \%$ da fortuna privada dos africanos se encontra no estrangeiro, bem como a principal parte da população mais educada, entre a qual 30000 doutorados!

Num dos seus World Economic Outlooks o FMI (1997) observa que a globalização tem servido para acentuar os beneficios das boas políticas e os malefícios das más políticas.

E aponta como principais determinantes do sucesso no desenvolvimento:

a) A qualidade da governação;

b) A estabilidade macroeconómica;

c) A abertura ao exterior e inserção na economia mundial;

d) A defesa ou protecção do direito de propriedade;

e) A qualificação da mão-de-obra.

Sendo a abertura ao exterior, especialmente para os pequenos países ou economistas, talvez o mais importante desses determinantes.

Pensa-se, assim, que a primeira e mais importante das tarefas e empreender para assegurar o desenvolvimento dos países mais pobres 
- e, também, a mais difícil - reside nas alterações que é necessário introduzir nesses mesmos países.

Seja como for, os efeitos negativos da globalização sobre alguns países e povos devem ser enfrentados, procurando minorá-los e compensá-los mediante políticas ou medidas apropriadas de cooperação por parte dos países mais avançados.

À cooperação multilateral é reconhecida como necessária pelo menos em duas frentes. A primeira respeita aos países menos desenvolvidos em risco de marginalização, pelo menos quando dispostos a introduzir ou adoptar políticas que permitam tornar eficaz a ajuda recebida, muito particularmente os países mais pobres e altamente endividados.

A segunda respeita à neutralização dos efeitos secundários negativos da globalização sobre esses países, como os respeitantes à degradação ambiental, aos problemas de saúde (epidemias e outros) e às migrações e situações de conflito. Os países mais desenvolvidos e as organizações internacionais podem contribuir muito para a melhoria da situação ambiental e sanitária, nomeadamente através da promoção de investigação orientada para a problemática destes países nos domínios da saúde, da agricultura e do combate à desertificação.

Estes e outros problemas que se põem à escala mundial, mesmo quando não sejam novos ou necessariamente associados à globalização, reclamam o fortalecimento da chamada Global Governance e uma maior e mais eficiente oferta de "bens públicos globais".

\section{O ALARGAMENTO DO FOSSO DAS DESIGUALDADES}

Um dos pecados, ou males, atribuídos à globalização é o do alargamento do fosso das desigualdades entre ricos e pobres, tanto entre países como dentro de um mesmo país. 
Com o desenvolvimento o grau de desigualdade no mundo, ou diferença de rendimento per capita entre os países mais ricos e os mais pobres ou desfavorecidos, tem-se alargado.

De acordo com as estimativas do especialistas em história económica Angus Maddison a diferença entre o rendimento médio nos vinte países mais ricos do mundo e o dos países mais pobres era de 2 para 1 apenas em 1820, quando ainda se não tinham sentido os efeitos da Revolução Industrial; de 5 para 1 no início do Séc. XX; de 20 para 1 no início dos anos 60 e de mais de 40 para 1 actualmente.

Poderá, porém, esse alargamento atribuir-se à globalização? Ou é parte do próprio processo de desenvolvimento, que oferece possibilidades crescentes àqueles que nele participam, deixando para trás ou marginalizando aqueles que nele se não inserem?

Há fenómenos de convergência ou de países pobres com economias a crescer a taxas bastante mais elevadas que a dos países industrialmente avançados, como foi o caso do Japão e dos "tigres" do Sudeste Asiático no passado e da China, Índia, Singapura, Malásia e Tailândia, na Ásia e do México e Chile na América Latina (entre outros países) actualmente.

Parece, assim, hoje possível retirar, de situações de pobreza extrema, massas imensas de população mundial num período relativamente curto, como se prevê ou se espera suceda nas próximas duas décadas na China (300 milhões) e na Índia.

Dois estudos recentes - um do Banco Mundial e outro de Freedom House ou Heritage Foundation - mostram de forma clara que a globalização ou inserção na economia mundial com abertura ao exterior contribui para a redução da pobreza e não para o alargamento do fosso entre ricos e pobres. Com efeito, as economias menos desenvolvidas, com maior abertura ao exterior, registaram na última década taxas de crescimento sensivelmente superiores, tanto às dos países que se fecharam ao exterior como às dos países mais ricos.

Existem países também pobres marginalizados do processo de crescimento com economias estagnadas ou em retrocesso, com 
rendimentos médios inferiores aos de há uma década atrás (55 países, 40 dos quais na África ao Sul do Sahará).

Ora, enquanto se verifica que a abertura ao exterior e a inserção na economia global é essencial ao crescimento, verifica-se igualmente que certo número de países se mostra incapaz de inserir-se nesse processo sem uma significativa ajuda externa.

De acordo com um estudo do Banco Mundial, verifica-se uma correlação positiva entre a abertura ao exterior e o crescimento num conjunto de países que representam $60 \%$ da população mundial, e uma correlação negativa nos restantes $40 \%$.

Os países pobres são mais vulneráveis às variações dos preços relativos das exportações e têm maior dificuldade em ajustar-se às transformações em curso na economia mundial, tendo sido particularmente afectados pela queda dos preços das matérias-primas desde o início do século XX.

A chamada Nova Economia e as novas tecnologias são também responsáveis pelo alargamento do fosso entre ricos e pobres, dado que os últimos não têm praticamente beneficiado das mesmas.

De acordo com um relatório recente da Organização Internacional do Trabalho (Life at Work in the Information Economy. ILO World Employment Report 2001) as novas tecnologias podem ajudar a aliviar situações de pobreza e contribuir para a melhoria da saúde, da educação e dos serviços sociais com custos mais reduzidos nos países pobres. Mas até agora aquilo que se tem verificado é a chamada "digital divide", havendo que fazer com que essa divisão seja ultrapassada.

Para além da exigência ética de solidariedade humana, especialmente no que toca às situações de pobreza extrema e de erradicação de flagelos epidémicos, a marginalização de um número significativo de países do processo de desenvolvimento põe ao resto do mundo importantes ameaças, como a da difusão de doenças, de fortes pressões migratórias e de terrorismo. Mas confronta sobretudo esses países com situações dramáticas e sem esperança de delas poderem sair sem a ajuda do exterior. Bastará referir que das seis 
dezenas de conflitos armados que deflagraram ou se arrastaram ao longo da década de 1989 a 1999 apenas três se desenvolveram em zonas não sujeitas a esse condicionalismo.

Ao mesmo tempo é confrangedor ver doenças como a malária, que podiam ser dominadas ou erradicadas com $1 / 10$ do custo anual das mesmas, continuarem a grassar em vários países de África. E que não chega a um décimo das despesas anuais com investigação médica a que é consagrada a problemas que afectam $9 / 10$ da população mundial.

A solução para estes problemas não é simples nem se encontra apenas no aumento da ajuda económica, que no ano findo atingiu o seu mínimo histórico. Mas não restam dúvidas de que se requer uma outra resposta do mundo desenvolvido, ou países ricos, reclamando-se uma acção colectiva devidamente programada da parte destes últimos.

Também se não justifica a manutenção por parte dos países industriais de todo um conjunto de restrições ainda existentes às importações provenientes dos países mais pobres, especialmente de produtos agrícolas e têxteis. E muitas dessas restrições são apoiadas e promovidas por grupos de pressão e manifestações anti-globalização, como as de Seatle, sob uma pretensa fundamentação ou motivação ética: a luta contra o trabalho infantil, os salários de miséria do Terceiro Mundo ou em condições que não respeitam as exigências ambientais.

São as imposições das chamadas cláusulas social e ambiental ou o "dumping social e ambiental" que são invocados para ocultar a defesa de interesses dos países ricos. Ou a pretensão de que a abertura às importações dos países pobres, de baixos salários, contribui para a baixa dos salários dos trabalhadores não qualificados nos países industriais - pretensão essa não confirmada nem pelos dados das organizações internacionais nem pela investigação efectuada em instituições independentes.

Assim, um estudo de Richard Freeman, de Harvard, conclui que quatro quintos do diferencial de salários entre os trabalhadores dos Estados Unidos e os mexicanos se encontram associadas a diferenças 
de qualificação da mão-de-obra e a diferenças entre as taxas de câmbio correntes e o poder de compra relativo das respectivas moedas.

De resto, esse diferencial tem ultimamente vindo a ser em parte colmatado nos Estados Unidos pela procura crescente de trabalho não qualificado e a redução do desemprego deste tipo de trabalhadores.

Por seu turno as importações dos países industrialmente avançados provenientes dos países menos desenvolvidos, não atingem normalmente mais que 3 a $8 \%$ do valor dos bens produzidos nos primeiros.

\section{CONCLUSÃO}

Não é a globalização e a adopção de novas tecnologias, com a abertura ao exterior, que tem tornado mais pobres os países pobres. Terá, sim, tornado mais ricos os países ricos. Mas há, felizmente, factores de esperança. Entre eles, uma consciência mais aguda da natureza dos problemas que afligem os países mais pobres e o reconhecimento também crescente da exigência ética de dar à globalização uma face mais humana, fazendo que ela contribua para a erradicação das situações de pobreza extrema, como um dos principais, senão o principal desafio, que se põe ao Mundo neste novo século.

Mas não pondo termo à globalização!

Ao contrário, a integração económica mundial pode contribuir de forma decisiva para a redução da parte da população mundial que vive em condições de pobreza extrema.

Pode argumentar-se que esse objectivo poderia igualmente atingirse mediante um processo de redistribuição de riqueza, uma vez que o montante de fundos requeridos para duplicar o rendimento per capita dos 1200 milhões de seres humanos mais pobres do planeta corresponde apenas a $2 \%$ do rendimento anual das economias dos países avançados. Mas a experiência tem mostrado que uma parte 
substancial, senão a quase totalidade, da ajuda oficial ao desenvolvimento tem sido simplesmente desperdiçada, não tendo sido senão um efeito mínimo sobre o desenvolvimento dos países mais pobres.

Essa ajuda continua a ser necessária e terá mesmo de ser aumentada. Mas em condições diferentes das do passado. E, ao mesmo tempo, sem parar o processo de integração e de abertura ao exterior que está na base da globalização.

Essa abertura e a inserção dos povos e das economias no processo de integração mundial em curso constitui condição necessária, embora não suficiente, de prosperidade das nações.

O problema não está pois em sustar o movimento de globalização em curso, mas sim em conseguir que os países pobres participem dos benefícios e oportunidades que o comércio mundial, o investimento directo estrangeiro e o acesso às novas tecnologias e saberes podem proporcionar.

Não restam dúvidas de que a comunidade internacional necessita de encontrar formas de conseguir que a globalização opere também em benefício dos mais pobres.

Como acentuou há pouco o Director Executivo do Fundo Monetário Internacional, num mundo cada vez mais interdependente a prosperidade dos povos não é sustentável se não for amplamente partilhada.

Ou, como lembrou o actual Pontífice, João Paulo II, na sua Mensagem para o Dia Mundial da Paz, a abertura dos mercados e o diálogo de culturas, no respeito mútuo e no reconhecimento dos valores universais que constituem o núcleo perene de todas as culturas, constituem um elemento essencial e um imperativo do progresso neste Novo Século. 
${ }^{1}$ Sobre este ponto vide Global Governance - Drawing the Insights from the Environmental Experience, edited by Oran R. Young. Mit Press Cambridge, Massachustts, Londres, 1997; Institutions and Economic Development, edited by Cristoper Claque, The Johns Hopkins University Press, Baltimore, 1997. 